\title{
Surprising finding of right-to-left shunt revealed with computed tomography angiography
}

\section{Kardos · M. Sagat - M. Kaldararova $\cdot$ P. Tittel $\cdot$ M. Nosal}

Published online: 10 March 2020

(C) The Author(s) 2020

A 2-year-old boy presented to our inpatient department with a history of recurrent lower respiratory tract infection and central cyanosis. His systemic saturation was between $75-80 \%$. Transthoracic echocardiography revealed no structural heart defect except for massive flow via dilated right pulmonary vein. Performed computed tomography angiography confirmed presence of this type of anomaly (Fig. 1). What is the diagnosis?

\section{Answer}

You will find the answer elsewhere in this issue.

M. Kardos $(\bowtie) \cdot$ M. Kaldararova $\cdot$ P. Tittel

Department of Functional Diagnostics, Children's Cardiac Center, Bratislava, Slovakia

kardi.marek@gmail.com

\section{Sagat $\cdot$ M. Nosal}

Department of Cardiac Surgery, Children's Cardiac Center,

Bratislava, Slovakia

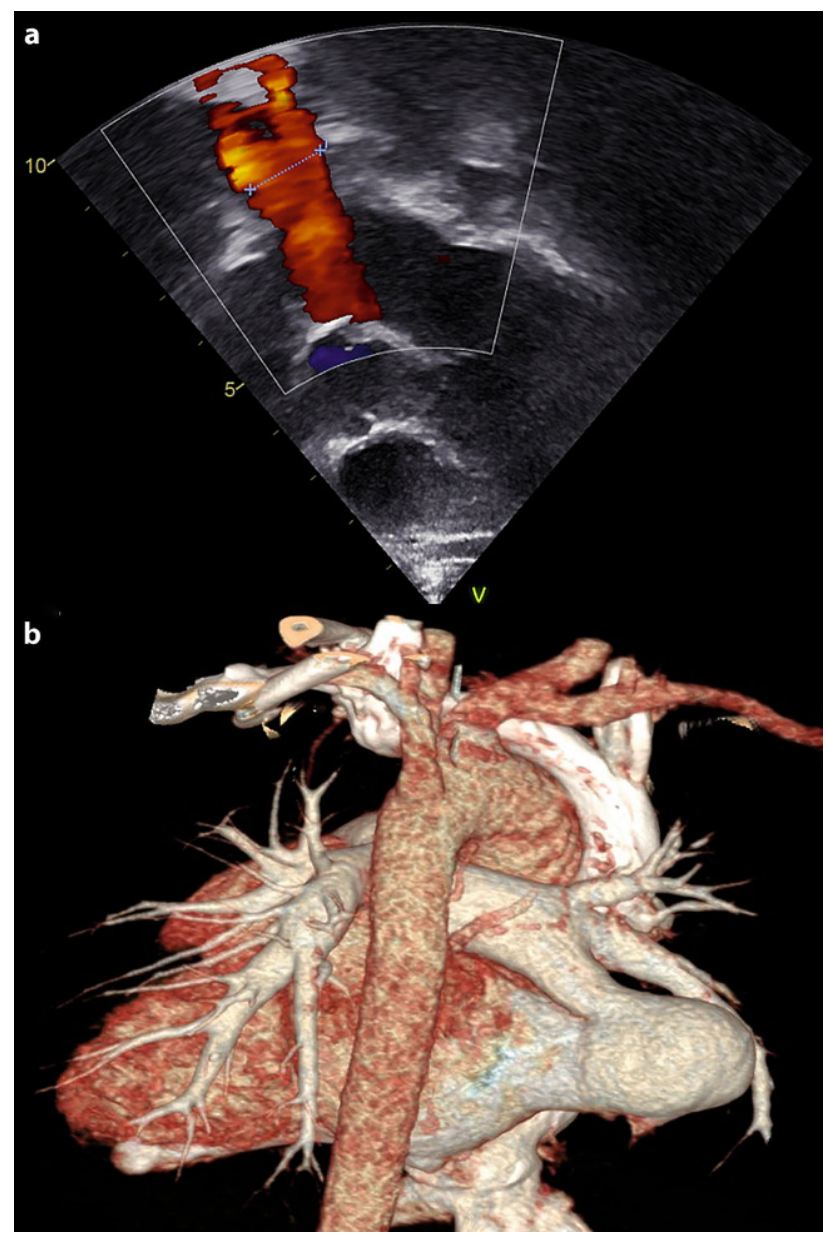

Fig. 1 a Colour Doppler study showing massive pulmonary vein flow from the right pulmonary vein. b Volume rendering technique reconstruction of performed computed tomography angiography with surprising finding 
Author Contribution M. Kardos was the major contributor in writing the manuscript and was also involved in drafting the manuscript. All authors read and approved the final manuscript.

Conflict of interest M. Kardos, M. Sagat, M. Kaldararova, P. Tittel and M. Nosal declare that they have no competing interests.

Ethical standards Permission to publish this case report was obtained from the parent(s) of the subject patient.

Open Access This article is licensed under a Creative Commons Attribution 4.0 International License, which permits use, sharing, adaptation, distribution and reproduction in any medium or format, as long as you give appropriate credit to the original author(s) and the source, provide a link to the Creative Commons licence, and indicate if changes were made. The images or other third party material in this article are included in the article's Creative Commons licence, unless indicated otherwise in a credit line to the material. If material is not included in the article's Creative Commons licence and your intended use is not permitted by statutory regulation or exceeds the permitted use, you will need to obtain permission directly from the copyright holder. To view a copy of this licence, visit http://creativecommons.org/licenses/by/4.0/. 